\title{
COMPARATIVE EVALUATION OF CLINICAL EFFICACY AND SAFETY OF SALBUTAMOL AND LEVOSALBUTAMOL MDI IN PATIENTS OF BRONCHIAL ASTHMA
}

Hitender Kumar, Ashok Goel, Nirmal Chand

1. Assistant Professor. Department of Pharmacology, SGRRIM \& HS, Dehradun .

2. Associate Professor. Department of Pharmacology, Government Medical college, Amritsar

3. Professor \& Head. Department of TB \& Chest Disease, Government Medical college, Amritsar

\section{CORRESPONDING AUTHOR}

Dr. Hitender Kumar,

Assistant Professor,

Department of Pharmacology,

SGRRIM \& HS, Patel Nagar, Dehradun

E-mail: hitender_kashyap@yahoo.co.in

Ph: 00917895291886

PURPOSE: Salbutamol is the most common $\beta 2$-agonist being currently used in the treatment of asthma. It was only available as a racemate, a 50:50 mixture of the dextro [(S)-salbutamol] and levo [(R)-salbutamol] rotatory forms. Regular and excessive use of racemate can induce paradoxical reactions in some subjects with asthma. The present study, compared MDI Salbutamol with levo [(R)-salbutamol] isomer over 8 weeks in terms of clinical efficacy and safety. METHODS: A prospective, parallel design, comparative study lasting eight weeks, involving 80 patient of either sex after taking their informed consent. Patients were randomly divided into 2 groups, A and B of 40 patients each. Patients in Group A and Group B were administered Salbutamol MDI two puffs $100 \mathrm{mcg}$ per puff four times daily and Levosalbutamol MDI two puffs each containing 50 mcg four times daily respectively. Rescue dose two or more puffs was allowed as required and the number of additional doses were counted by patients. Observations were made and analyzed at 0,4 and 8 weeks for FEV1, FVC, and PEFR and side effects. RESULTS: Highly significant $(\mathrm{p}<0.001)$ mean percent change in FEV1, FVC and PEFR at 4 and 8 weeks of Group B (Levosalbutamol) patients as compared to mean percent change in FEV1 of Group A (Salbutamol) patients at 4 weeks and 8 weeks. CONCLUSION: High therapeutic efficacy was observed with the use of the Levosalbutamol MDI with lesser side effects.

Clinical Implications: Levosalbutamol can be preferred over salbutamol for better control of symptoms.

KEYWORDS: Salbutamol, levosalbutamol, MDI, S-salbutamol, R-salbutamol, RAC ; Racemate

Worldwide 300 million people currently have asthma. The estimates suggest that asthma prevalence increases globally by $50 \%$ every decade. ${ }^{1}$

The prevalence of asthma in affluent countries appears to have stabilized. In developing countries, there is a rising incidence that appears to be associated with increased urbanization. The prevalence of atopy and other allergic diseases has also increased over the same time, suggesting that the reasons for the increase are likely to be systemic rather than confined to the lungs. ${ }^{2}$

The drugs used most commonly in the treatment of asthma, are $\beta_{2}$ adrenergic receptor agonists. Although human bronchial smooth muscle receives little or no sympathetic 
innervation, it nevertheless contains large numbers of, $\beta_{2}$ adrenergic receptors. ${ }^{3}$ Salbutamol is the most common $\beta_{2}$-agonist being used currently in the treatment of asthma. Previously it was only available as a racemate, a 50:50 mixture of the dextro [(S)-salbutamol] and levo [(R)salbutamol] rotatory forms. The racemate could serve the same function at double the dose with little adverse effects then what was the need to synthesize (R)-salbutamol as an individual drug, this question might arise. ${ }^{4}$

Continuous exposure to RS- and S-salbutamol increases bronchial responsiveness to a range of stimuli, an effect not attributed to $\beta$-adrenoceptor occupancy or desensitization. ${ }^{5} \mathrm{~S}$ Salbutamol neither activate $\beta_{2}$ adrenoceptors nor it has any clinically meaningful ability to relax airway smooth muscle. It also does not modify activation of $\beta_{2}$ adrenoceptors by (R)-salbutamol. For many years it was thought to be biologically inert. Recently, it has been established that regular and excessive use of RAC induces paradoxical reactions in some subjects with asthma. This has led to development of safer and therapeutically active agents of the available $\beta_{2}$ agonists. Consequently, "Levosalbutamol" was approved. ${ }^{6}$

S-Salbutamol causes increased airway hyper-responsiveness: Bronchoconstriction, leading to airway obstruction and development of airway hyper-responsivenes are major hallmarks of asthma. A number of studies have suggested that chronic dosing with racemate for many months may results in increased bronchial hyperresponsiveness in some asthmatics.7,8

The mechanism underlying is not clear but it is suggested that S-salbutamol causes bronchial hyperresponsivenes by a cholinergic dependent $\beta_{2}$ adrenergic independent mechanism". ${ }^{9}$ This is further suggested when S-salbutamol or R-salbutamol is exposed to isolated human bronchus, S-salbutamol enhances and R-salbutamol inhibits the contractile response of histamine and leukotriene $\mathrm{C} 4 .^{10}$

In another study, tracheal smooth muscle cells incubated with (R)-salbutamol undergo a dose dependent reduction in intracellular calcium concentration. In contrast, exposure to either racemic salbutamol or (S)-salbutamol results in increased intracellular calcium concentration. This effect of (S)-salbutamol is not inhibited by the $\beta 2$-blocker ICI-118,551 but is suppressed by the muscarinic receptor antagonists, atropine and 4-diphenylace-toxy- $\mathrm{N}$ methylpiperidine. ${ }^{11}$

Markedly elevated plasma levels of S-isomer are seen after repeated oral or inhaled dosing with racemic salbutamol and with time, racemic salbutamol becomes predominantly S-salbutamol secondary to stereoselective metabolism. ${ }^{12,13}$

In this study we have compared the clinical efficacy and safety of levosalbutamol and salbutamol and to see the effect of these two drugs over a period of eight weeks in patients of bronchial asthma.

MATERIALS AND METHODS: In this study 80 patients in the age group of 15 to 60 years suffering from bronchial asthma visiting the OPD/wards of Department of Tuberculosis and Chest Diseases attached to Government Medical College, Amritsar were included.

INCLUSION CRITERIA: Reversibility of airway obstruction ( $>15 \%$ reversibility of FEV1 after 2 puffs of inhaled salbutamol), absence of Respiratory tract infections, patient not receiving inhaled/systemic glucocorticoids for previous 2 weeks. 
EXCLUSION CRITERIA: Irreversible airway obstruction, Cor pulmonale, steroid dependent asthma, Ischaemic heart disease, tuberculosis, pregnant and lactating mothers, diabetes mellitus, severe hypertension

The protocol of the study was submitted to the Institutional Ethics Committee and approval was granted by Baba Farid University of Health and Sciences. Written informed consent was obtained from all the recruited patients included in the present study. Study was prospective, parallel design, comparative, intention to treat study patients lasting eight weeks. Patients suffering from mild to moderate stable asthma were included in the study after obtaining their informed consent. Patients were divided randomly (using table of random numbers) into two groups of 40 each, (group A and group B). Detailed history in relation to episodic breathlessness, cough, wheezing, expectoration, any family history of asthma was taken. History regarding past use of slbutamol, long term intake of steroids or any drug allergy was taken.

Asthma symptom score was noted at the beginning of the study and after 4 and 8 weeks of follow up. General physical examination and routine laboratory investigations of all patients was done. Every patient was subjected to X-ray PA view to rule out bronchiectasis, ABPA, tuberculosis, cystic fibrosis or any cardiac problem.

SPIROMETERY: FVC (Forced vital capacity), FEV 1 (Forced expiratory volume in 1 second) PEFR (Peak expiratory flow rate) were done in each case at the start of study (basal), at 4 weeks and at 8 weeks of follow up.

Adequate time was spent in training the recruited subjects for the study in use of MDI. All the steps were explained in vernacular language by using placebo MDIs. Patients were assessed on day zero at the baseline for FVC, FEV1 and PEFR on computerized spirometery without MDI and 20 minutes after administering 2 puffs of respective MDI.

Patients in group A and group B were prescribed Salbutamol and Levosalbutamol MDI respectively. Group A: Salbutamol Metered Dose Inhaler (100 microgram per actuation) two puffs four times a day. Group B: Levosalbutamol Metered Dose Inhaler (50 microgram per actuation) two puffs four times a day. Patients were instructed to keep a record of additional doses if needed per week in a diary maintained by the patient. Now patients were instructed about the use of MDI. Patients were asked to exhale to the maximum through mouth and to take a deep inspiration through the mouth piece of MDI maintaining a tight lip seal and actuating simultaneously. Nostrils were closed with a clip. Breath holding for about 10 seconds or as long as comfortable was required for proper disposition of the drug in lungs. After administering two puffs of respective MDI in respective patient, a second reading on spirometer was taken after a time interval of 20 minutes. Percentage increase in value of FVC, FEV 1 , PEFR from baseline was calculated by using formula:

Percentage $=\quad$ Post Medication Reading - Pre Medication Reading

Pre Medication reading

RESULTS: In group A mean age among male patients was $41.78 \pm 10.8$ years, in female patients it was $39.71 \pm 11.8$ years. In group B mean age among male patients was $39.65 \pm 12.0$ years and in female patients it was $37.53 \pm 11.9$ years. 
GROUP A (Salbutamol): As shown in table 1, fig. 1, the percent change in $\mathrm{FEV}_{1}$ at 8 week is, this value was significantly $(\mathrm{p}<0.05)$ lower than that of percent change at 0 week. Percent change in FVC at 4 and 8 week it was not statistically significant. Percent change in PEFR at 4 week, the change is significant $(p<0.05)$. Whereas when percent change in PEFR was compared with percent change at 8 week, it is not statistically significant $(p>0.05)$.

GROUP B (Levosalbutamol): As shown in (table 2, fig.2), on comparing these values by applying paired t test this change was significant $(p=0.05)$. Whereas the percent change in $\mathrm{FEV}_{1}$ at 8 week was highly significant $(p<0.001)$ than that of percent change at 0 week. On comparing percent change in FVC at 4 and 8 week it was not statistically significant.

Percent change in PEFR at 4 week was highly significant $(\mathrm{p}<0.001)$. Increase in percent change in PEFR was compared with percent change in PEFR at 8 week, it was also highly significant statistically $(\mathrm{p}<0.001)$.

As shown in fig 3, at 4 weeks mean percent change in $\mathrm{FEV}_{1}$ of Group B was significantly higher $(p<0.001)$ than Group A. At 8 weeks mean percent change in $\mathrm{FEV}_{1}$ of Group B was significantly higher $(\mathrm{p}<0.001)$ than Group A.

As shown in fig. 4, at 4 weeks mean percent change in PEFR of Group B was significantly higher $(p<0.05)$ than Group A. At 8 weeks mean percent change in PEFR of Group B was significantly higher $(p<0.001)$ than Group A. As shown in fig. 5, symptom score at 0 and 4 weeks of both the Groups was not statistically significant. At 8 weeks, symptom score of Group B patients was significantly lower than group a patients $(p<0.05)$. Night awakenings were also significantly lower in Group B patients as compared to Group A patients at 4 and 8 weeks. Use of rescue doses by Group B patients was significantly less than Group A patients at 8 weeks ( $p<$ $0.05)$

\section{DISCUSSION}

\section{Group A versus Group B}

\section{FEV $_{1}$}

At 4 and 8 weeks mean percent change in $\mathrm{FEV}_{1}$ of Group B patients was significantly higher $(\mathrm{p}<0.001)$ than mean percent change in $\mathrm{FEV}_{1}$ of Group A patients. It is highly significant.

FVC

At 4 and 8 weeks mean percent change in FVC of Group B is significantly higher $(p<0.05)$ than Group A

PEFR

At 4 weeks mean percent change in PEFR of Group B was higher $(p<0.05)$ than Group A. At 8 weeks mean percent change in PEFR of Group B was higher than Group A ( $<<0.001)$

Regular and excessive use of racemate can induce paradoxical reactions in some subjects with asthma. Continuous exposure to RS- and S-salbutamol increased bronchial responsiveness to a range of stimuli, an effect not attributed to $\beta$-adrenoceptor occupancy or desensitization. ${ }^{14} \mathrm{~S}$ Salbutamol does not activate $\beta_{2}$ adrenoceptors and do not have any clinically meaningful ability to relax airway smooth muscle.

S-salbutamol enhances and R- salbutamol inhibits the contractile response of histamine and leukotriene $\mathrm{C} 4 . .^{15}$ Long term use of S-salbutamol may be responsible for decreased bronchodilator effect. A randomised, double-blind, placebo-controlled crossover study was conducted in patients with mild asthma who were randomised to receive cumulative doses of 
levosalbutamol, (S)-salbutamol, racemic salbutamol or placebo every 20 min on 4 separate days. Pulmonary function testing was completed after each dose. The authors showed that all of the bronchodilation was achieved by levosalbutamol but found no detrimental effects of (S)salbutamol. The bronchodilation observed in the ascending, consecutive dose regimens was similar for levosalbutamol and racemic salbutamol, and systemic effects were dependent on (R)salbutamol, whether this was delivered as a single isomer or in a racemic mixture. The short duration of this protocol is not likely to have resulted in the accumulation of the (S)-isomer. ${ }^{16}$

Patients in another study, who were $>12$ years of age, received either levosalbutamol 0.63 or $1.25 \mathrm{mg}$, an equivalent dose of racemic salbutamol (1.25 or $2.5 \mathrm{mg}$ ) or placebo by nebulisation three times per day for 28 days. End points were efficacy, expressed as mean percentage change from baseline in forced expiratory volume in $1 \mathrm{~s}\left(\mathrm{FEV}_{1}\right)$ after4 weeks, and safety. Levosalbutamol $1.25 \mathrm{mg}$ was the most effective, with a statistically significant change compared with other regimen observed at first dose and a numerically higher response at day $28 .{ }^{17}$

CONCLUSION: Levosalbutamol has more efficacy in controlling the acute symptoms of bronchial asthma. Long term use of salbutamol may be responsible for uncontrolled symptoms of bronchial asthma due to its S-isomer. Studies are required to be done in larger number of subjects to see the negative effects of S-isomer.

ACKNOWLEDGEMENT: Thanks to Cipla Limited for providing medicines.

\section{REFERENCES}

1. Masoli, M, Fabian, D, Holt, S, et al Global Initiative for Asthma (GINA) program: the global burden of asthma: executive summary of the GINA Dissemination Committee report. Allergy 2004; 59,469-478.

2. Barnes PJ. Asthma. In: Kasper D.L., Fauci A.S., Longo D.L., Braunwald E., Hauser S.L., Jameson J.L., editors. Harrison's Principles Of Internal Medicine. 16 $6^{\text {th }}$ ed. London: McGraw-Hill Medical Publishing Division; 2005. p. 201-5.

3. Undem BJ. Pharmacotherapy of Asthma In: Brunton LL, Lazo JS, Parker KL, editors. Goodman and Gilman's: The Pharmacological Basis of Therapeutics. 11 th Edition. New York: Mc Graw Hill; 2006:717-720.

4. Pesola GR, D`Costa VC. Albuterol or levalbuterol for the treatment of asthma. The internet journal of asthma. Allergy and immunology. 2004; 3 (1).

5. Keir S, Page C, Spina D. Bronchial hyperresponsiveness induced by chronic treatment with salbutamol: role of sensory nerves. J Allergy Clin Immunol. 2002; 110:388-394.

6. Van Essen-Zandvliet EE, Hughes MD et al. Effects of 22 months of treatment with inhaled salbutamol lung function, airway responsiveness, and symptom in children with asthma. Am Rev Resp Dis 1992; 146:547-554.

7. Waheda I, Wong CS, Wisniewski Afz et al. Asthma control during and after cessation of regular $\beta 2$ agonist treatment. Am Rev Resp Dis 1993; 148:707-712.

8. Taylor DR, Sears MR. Bronchodilators and bronchial hyper- responsiveness. Thorax 1994; 49(2):190-191. 
9. Mazzoni L, Naef R, Chapman ID, Morley J. Hyper -responsiveness of the airways to histamine following exposure of guinea pigs to racemic mixtures and distomers of $\beta 2$-selective sympathomimetics. Pulm Pharmacol 1994; 7:367-376.

10. Templeton AGB, Chapman ID, Chilvers E, Morley J, Handley DA. Effects of (S)-albuterol on isolated human bronchus. Pulm Pharmacol 1998; 11: 1-6.

11. Mitra S, Ugur M, Ugur O, Goodman HM, Mccullough JR, Yamaguchi H: (S)-Albuterol increases intracellular free calcium by muscarinic receptor activation and a phospholipase C-dependent mechanism in airway smooth muscle. Mol. Pharmacol. (1998) 53:347-354.

12. Boulton DW, Fawcett JP. Enantioselective disposition of salbutamol in man following oral and inhaled administration. J Clin Pharmocol 1996; 41: 35-40.

13. Schmekel B, Rydberg I, Norlandar B, Sjosward KN. Stereoselective pharmacokinetics of S-salbutamol after administration of the racemate in healthy volunteers. Eur Respir J 1999; 13:1230-1235.

14. Keir S, Page C, Spina D. Bronchial hyperresponsiveness induced by chronic treatment with salbutamol: role of sensory nerves. J Allergy Clin Immunol. 2002; 110:388-394.

15. Walle T, Walle UK, Thornburg KR, Schey KL. Stereoselective sulfation of albuterol in humans. Drug Meabo Dispos 1993; 21:76-80.

16. Lotvall J, Palmqvist M, Arvidsson P, Maloney A, Ventresca GP, Ward J: The therapeutic ratio of R-albuterol is comparable with that of RS-albuterol in asthmatic patients. J. Allergy Clin. Immunol. (2001) 108:726-731.

17. Pleskow WW, Nelson HS, Schaefer K, Claus R, Roach JM: Pairwise comparison of levalbuterol versus racemic albuterol in the treatment of moderate-to severe asthma. Allergy Asthma Proc. (2004) 25:429-436.

TABLE 1 Percent change in FEV ${ }_{1}$, FVC and PEFR (Mean \pm SD) after inhalation of two puffs of Salbutamol

\begin{tabular}{|c|c|c|c|}
\hline Percent change & 0 Week & 4 Week & 8 Week \\
\hline FEV $_{1}$ & $38.24 \pm 6.34$ & $35.96 \pm 5.3$ & $34.23 \pm 8.16$ \\
\hline FVC & $26.05 \pm 4.93$ & $26.46 \pm 5.57$ & $26.75 \pm 6.43$ \\
\hline PEFR & $41.82 \pm 6.91$ & $45.71 \pm 7.7$ & $44.56 \pm 7.57$ \\
\hline
\end{tabular}

TABLE II Percent change in FEV 1 , FVC and PEFR (Mean \pm SD) after in inhalation of two puffs of Levosalbutamol

\begin{tabular}{|c|c|c|c|}
\hline Percent change & 0 Week & 4 Week & 8 Week \\
\hline FEV $_{1}$ & $40.11 \pm 5.2$ & $42.31 \pm 3.5$ & $44.00 \pm 4.4$ \\
\hline FVC & $31.40 \pm 5.11$ & $30.76 \pm 6.18$ & $30.71 \pm 5.18$ \\
\hline PEFR & $46.17 \pm 5.2$ & $50.41 \pm 3.7$ & $53.55 \pm 4.3$ \\
\hline
\end{tabular}


(Fig. 1) Group A : Mean Percent change in LFT at 0,4 and 8 week

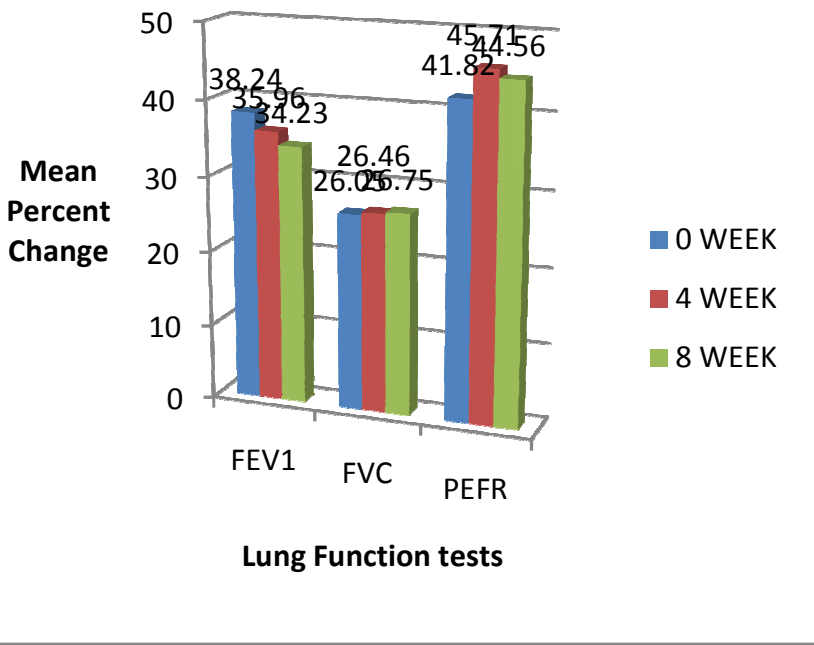

(Fig. 2) Group B : Mean Percent change in LFT at 0,4 and 8 week

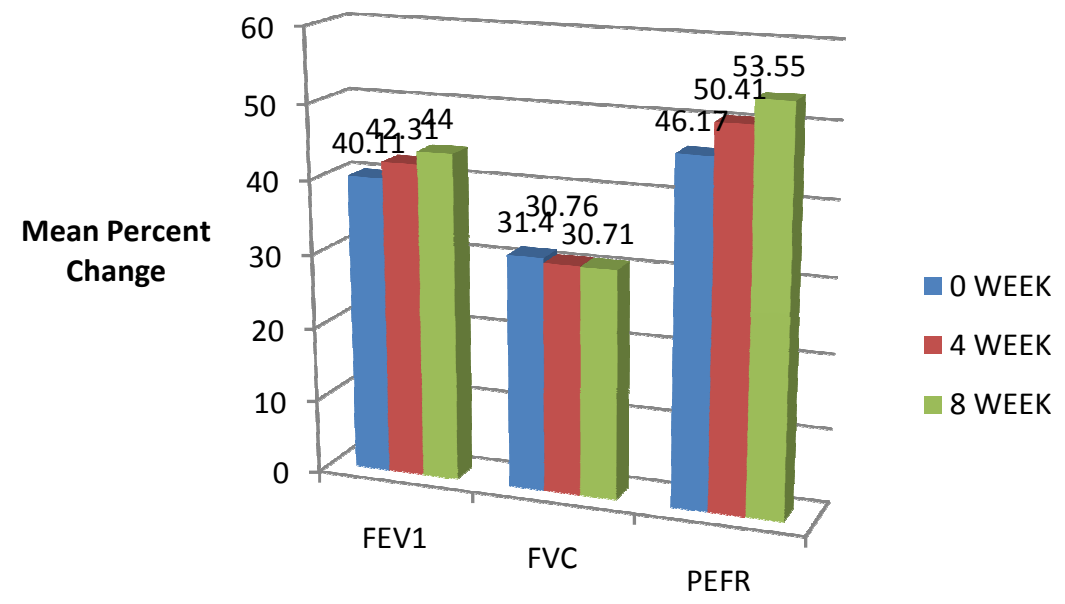

Lung Function tests 
(Fig.3) FEV $_{1}$ : Group A vs Group B

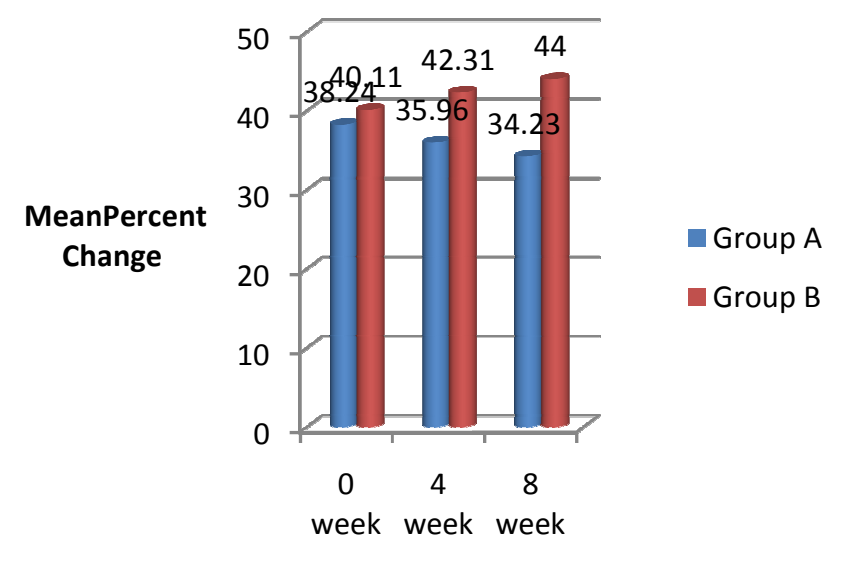

\section{(Fig. 4) PEFR : Group A vs Group B}

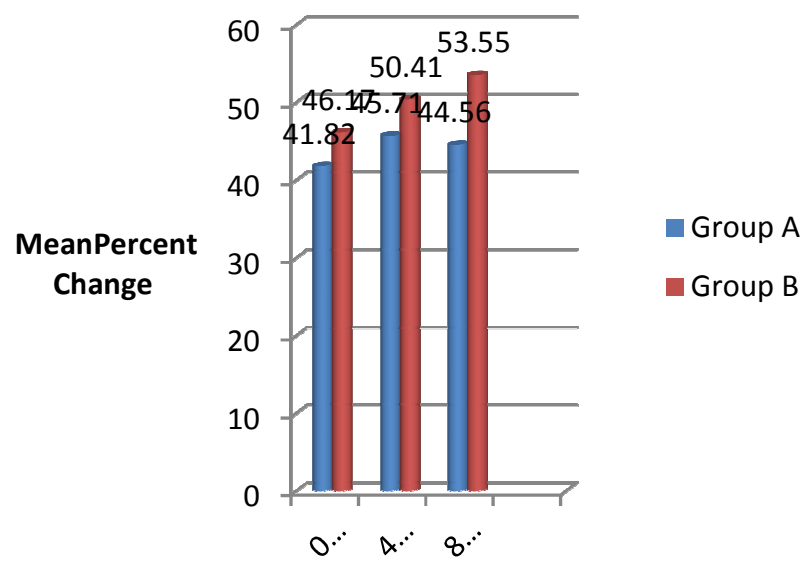


(Fig.5) Symptom score : Group A vs Group B

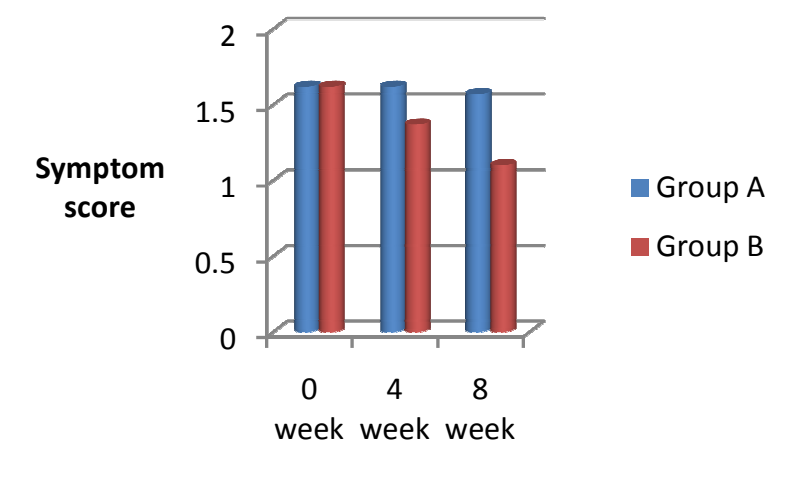

